\title{
Editorial
}

\section{Nanotechnology for Energy and Environment}

\author{
J. M. P. Q. Delgado, ${ }^{1}$ Andreas Öchsner, ${ }^{2,3}$ and A. G. Barbosa de Lima ${ }^{4}$ \\ ${ }^{1}$ Laboratory of Building Physics (LFC), Civil Engineering Department, Faculdade de Engenharia da Universidade do Porto, \\ Rua Dr. Roberto Frias s/n, 4200-465 Porto, Portugal \\ ${ }^{2}$ School of Engineering, Griffith University, Gold Coast Campus, Southport 4222, Australia \\ ${ }^{3}$ School of Engineering, The University of Newcastle, Callaghan, NSW 2308, Australia \\ ${ }^{4}$ Department of Mechanical Engineering, Federal University of Campina Grande, 58429-900 Campina Grande, PB, Brazil \\ Correspondence should be addressed to J. M. P. Q. Delgado; jdelgado@fe.up.pt
}

Received 19 May 2014; Accepted 19 May 2014; Published 25 June 2014

Copyright (C) 2014 J. M. P. Q. Delgado et al. This is an open access article distributed under the Creative Commons Attribution License, which permits unrestricted use, distribution, and reproduction in any medium, provided the original work is properly cited.

Nanotechnology is the engineering of functional systems at the molecular scale. While nanomaterials have been a part of our everyday life for quite some time, the past two decades have witnessed a fast growth of the nanotechnology sector. Nanotechnology is being used in several applications to improve the environment and to produce more efficient and cost-effective energy, such as generating less pollution during the manufacture of materials, producing solar cells that generate electricity at a competitive cost, cleaning up organic chemicals polluting groundwater, and cleaning volatile organic compounds (VOCs) from air.

In this special issue the papers presented are devoted to the following. First is nanomaterials for building and construction, namely, a numerical and sensitivity analysis of the enthalpy and melting temperature effect on the inside building comfort sensation potential of the plastering mortar phase change materials (PCM). Building components with incorporated PCM are meant to increase heat storage capacity and enable stabilization of interior buildings surface temperatures whereby influencing the thermal comfort sensation and the stabilization of the interior ambient temperatures $[1,2]$. Second is nanotechnology for water treatment, such as a review of the possible applications of the nanoparticles/fibers for the removal of pollutants from water/wastewater. The work presented overviews the availability and practice of different nanomaterials for removal of great number pollutants present in surface water, ground water, and industrial water. Several recommendations are made based on the current practices of nanotechnology applications in water industry. Third work presents the separation of $\mathrm{TiO}_{2}$ photocatalyst nanoparticle. The results showed that flocculation of $\mathrm{TiO}_{2}$ nanoparticles is influenced by ionic strength and $\mathrm{pH}$. Fourth is nanotechnology for electrochemical conversion and energy storage, such as the progress update with the development of nanodielectric composites with electric field tunability for various high energy and high power electrical applications. Fifth is nanostructures, such as the numerical analysis of several zigzag and armchair single-walled carbon nanotubes (CNTs), to study the vibrational behaviour. The results presented showed that natural frequency of straight armchair and zigzag CNTs increases with the increase of the chiral number of both armchair and zigzag CNTs. It was also revealed that the natural frequency of CNTs with higher chirality decreases by introducing bending angles [3, 4]. Sixth is nanomaterials for solar cells, namely, the utilization of nanostructure graphene thin films as electron transfer layer in dye-sensitized solar cells. Those materials are of particular interest in the field of solar energy owing to their low cost and simplicity of fabrication. Seventh is nanocomposites, namely, the influence of processing type in the morphology of membranes obtained from PA6/MMT nanocomposites. Nanocomposites have an extensive use in the current process of membrane preparation, taking into account their unique features as membranes. Eighth paper presents the evaluation of thermomechanical behaviour during heating of nanocomposites of epoxy resin containing bentonite clay. 
We hope that readers will find in this special issue not only accurate data and updated reviews on the nanotechnology field area but also important questions to be resolved. This special issue includes both theoretical and experimental developments, providing a self-contained major reference that is appealing to both the scientists and the engineers. At the same time, these topics will be going to the encounter of a variety of scientific and engineering disciplines, such as chemical, civil, agricultural, and mechanical engineering.

\author{
J. M. P. Q. Delgado \\ Andreas Öchsner \\ A. G. Barbosa de Lima
}

\title{
References
}

[1] P. Ahadi, "Applications of nanomaterials in construction with an approach to energy issue," Advanced Materials Research, vol. 261-263, pp. 509-514, 2011.

[2] A. V. Sá, M. Azenha, H. De Sousa, and A. Samagaio, “Thermal enhancement of plastering mortars with Phase Change Materials: experimental and numerical approach," Energy and Buildings, vol. 49, pp. 16-27, 2012.

[3] A. Ghavamian and A. Öchsner, "Numerical modeling of eigenmodes and eigenfrequencies of single- and multi-walled carbon nanotubes under the influence of atomic defects," Computational Materials Science, vol. 72, pp. 42-48, 2013.

[4] M. Farsadi, A. Öchsner, and M. Rahmandoust, "Numerical investigation of composite materials reinforced with waved carbon nanotubes," Journal of Composite Materials, vol. 47, no. 11, pp. 1425-1434, 2013. 

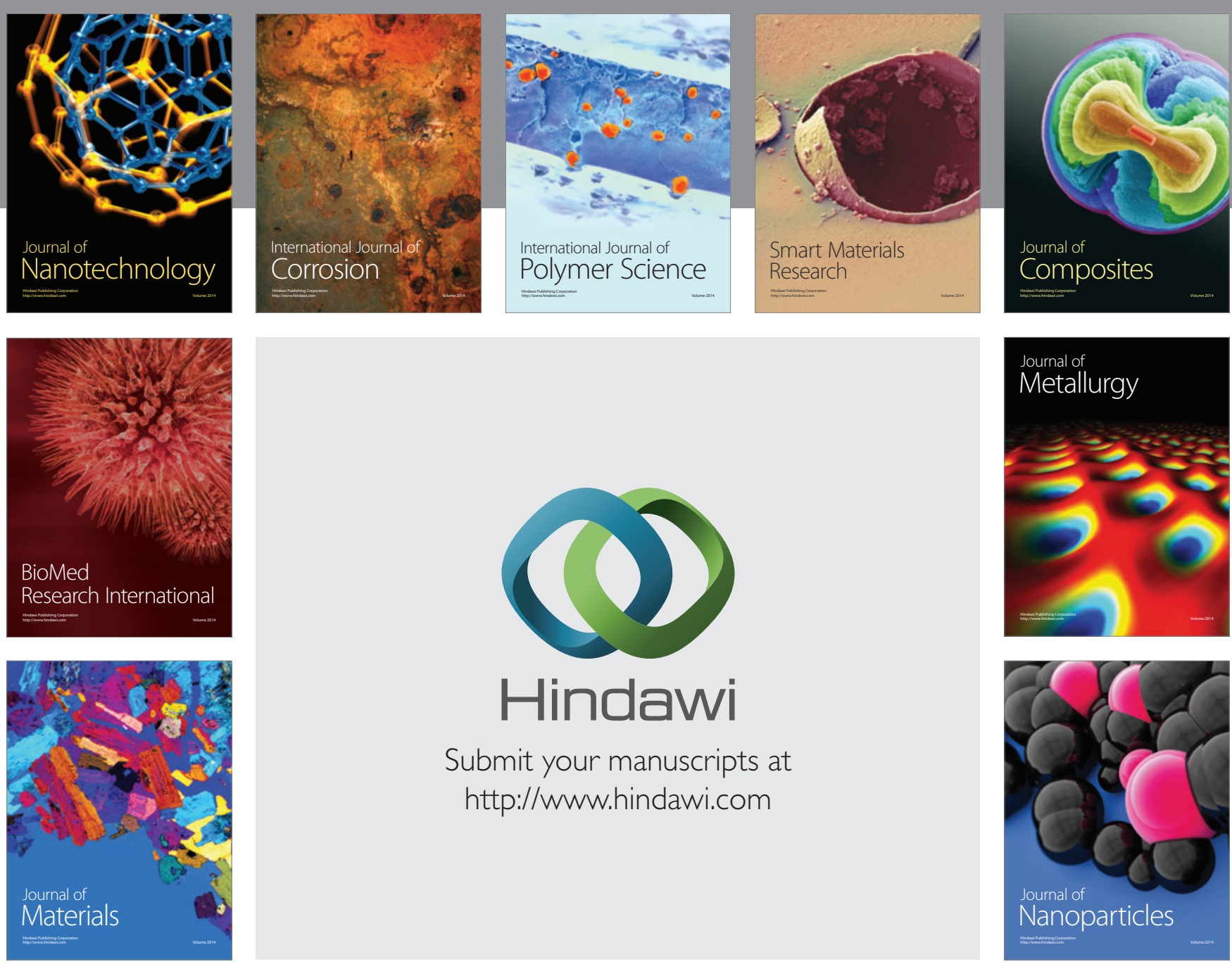

Submit your manuscripts at http://www.hindawi.com
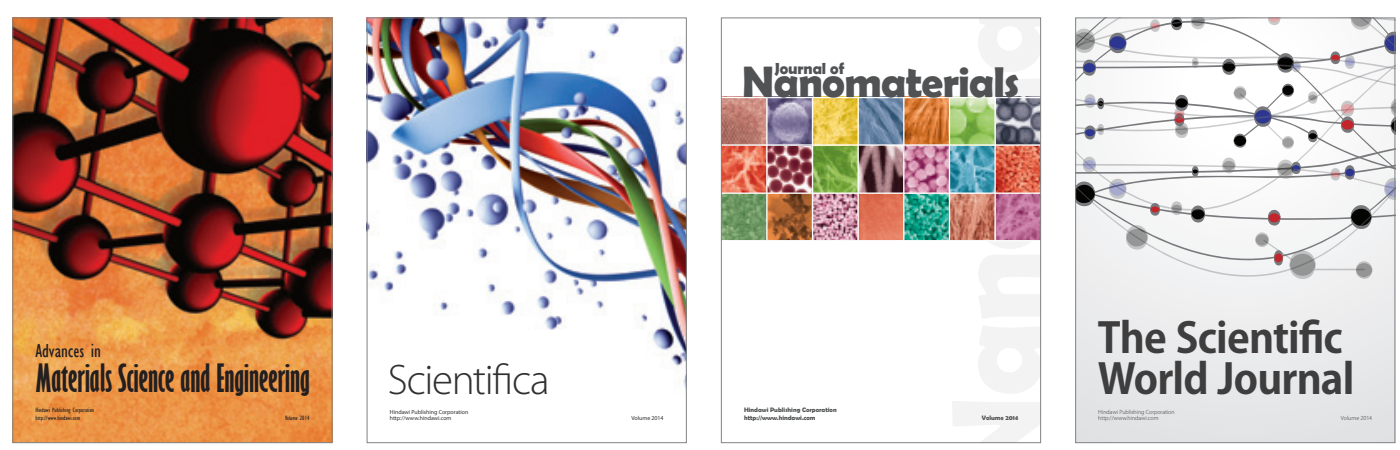

\section{The Scientific World Journal}
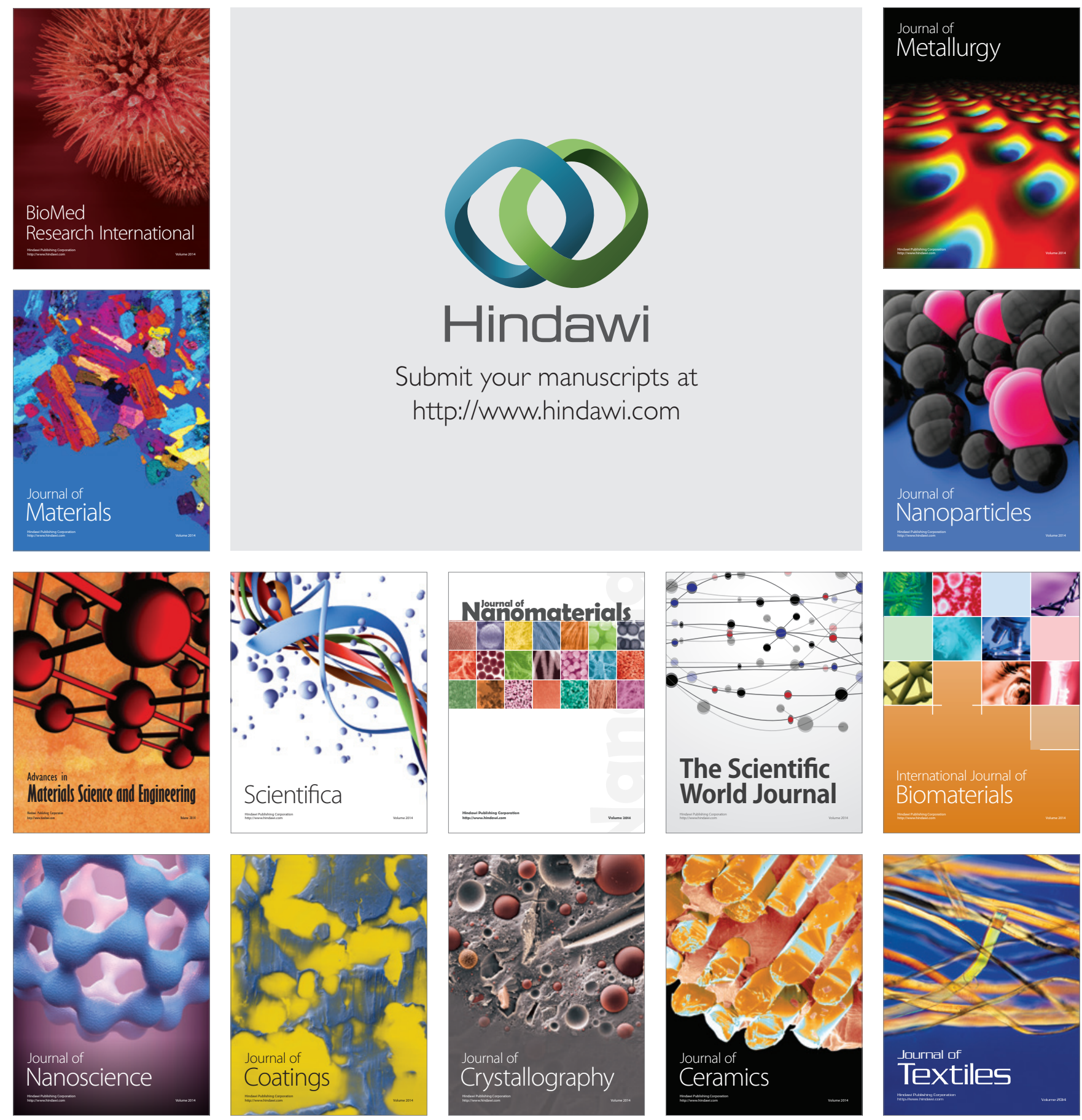